This is the final peer-reviewed accepted manuscript of:

Madzaric, S., Ceglie, F., Depalo, L., Al Bitar, L., Mimiola, G., Tittarelli, F., Burgio, G. (2018). Organic vs. organic - soil arthropods as bioindicators of ecological sustainability in greenhouse system experiment under Mediterranean conditions. Bulletin of Entomological Research, 108(5), 625-635.

The final published version is available online at:

https://doi.org/10.1017/S0007485317001158

This version is published under a Creative Commons CC-BY-NC-ND. No commercial re-distribution or re-use allowed. Derivative works cannot be distributed.

(C) Cambridge University Press 2017 


\title{
Organic vs. organic - soil arthropods as bioindicators of ecological sustainability in greenhouse system experiment under Mediterranean conditions
}

\author{
Suzana Madzaric ${ }^{1,2 *}$, F.G. Ceglie ${ }^{2}$, L. Depalo ${ }^{3}$, L. Al Bitar ${ }^{2}$, \\ G. Mimiola ${ }^{2}$, F. Tittarelli ${ }^{4}$ and G. Burgio ${ }^{3}$ \\ ${ }^{1}$ Dipartimento di Science per l'Ambiente, Università degli Studi di Napoli \\ 'Parthenope' Centro Direzionale, Isola C4, 80143 Napoli, Italy: ${ }^{2}$ CIHEAM - \\ Mediterranean Agronomic Institute of Bari, via Ceglie 9, 70010 - Valenzano \\ (BA), Italy: ${ }^{3}$ Dipartimento di Scienze Agrarie-Entomologia, Università di \\ Bologna, viale Fanin 42, 40127 Bologna, Italy: ${ }^{4}$ Consiglio per la ricerca in \\ agricoltura e l'analisi dell'economia agraria-Centro di ricerca per lo studio \\ delle relazioni tra pianta e suolo CREA - RPS, Rome, Italy
}

\begin{abstract}
Organic greenhouse (OGH) production is characterized by different systems and agricultural practices with diverse environmental impact. Soil arthropods are widely used as bioindicators of ecological sustainability in open field studies, while there is a lack of research on organic production for protected systems. This study assessed the soil arthropod abundance and diversity over a 2-year crop rotation in three systems of OGH production in the Mediterranean. The systems under assessment differed in soil fertility management: SUBST - a simplified system of organic production, based on an input substitution approach (use of guano and organic liquid fertilizers), AGROCOM - soil fertility mainly based on compost application and agroecological services crops (ASC) cultivation (tailored use of cover crops) as part of crop rotation, and AGROMAN - animal manure and ASC cultivation as part of crop rotation. Monitoring of soil fauna was performed by using pitfall traps and seven taxa were considered: Carabidae, Staphylinidae, Araneae, Opiliones, Isopoda, Myriapoda, and Collembola. Results demonstrated high potential of ASC cultivation as a technique for beneficial soil arthropod conservation in OGH conditions. SUBST system was dominated by Collembola in all crops, while AGROMAN and AGROCOM had more balanced relative abundance of Isopoda, Staphylinidae, and Aranea. Opiliones and Myriapoda were more affected by season, while Carabidae were poorly represented in the whole monitoring period. Despite the fact that all three production systems are in accordance with the European Union regulation on organic farming, findings of this study displayed significant differences among them and confirmed the suitability of soil arthropods as bioindicators in protected systems of organic farming.
\end{abstract}

Keywords: organic greenhouse, agroecological services crops, agroecology, Staphylinidae

*Author for correspondence

Phone: +39 (342) 134-7169

Fax: +39 (080) 4606-210

E-mail: smbmancic@gmail.com
Introduction

Awareness about the food and environmental quality of organic production is increasing at society level and people are becoming more concerned about sustainability, 
environmental impacts, and health effects of intensive farming (Randall \& James, 2012). On the other side, according to some authors, organic farming is becoming a slightly modified version of conventional agriculture, substituting the inputs to fit with regulation and not considering abovementioned concerns (Hall \& Mogyorody, 2001; Goldberger, 2011).

When demonstrating the benefits of organic farming on beneficial fauna including soil arthropods, most of the studies has to start with the two well-known meta-analyses of Hole et al. (2005) and Bengtsson et al. (2005). Organic farming in protected systems of cultivation (i.e. greenhouse production) is characterized by diverse structures and conditions (depending on the zone, region, country, etc.) and displays fewer examples of specific studies compared with the open field. The food-web structures, including soil interactions, also have been less studied in organic greenhouse $(\mathrm{OGH})$ production (Smeding \& de Snoo, 2003), having a lack of studies concerning soil arthropods.

The importance of soil arthropods in soil and agroecosystem processes has been well recognized, due to their high biodiversity, abundance, and their important role as predators of pests and soil organic matter decomposers (Van Straalen, 1998; Bohac, 1999; Kromp, 1999; Andre et al., 2002). Beside their roles in ecosystem functioning, they respond to a variety of environmental and ecological factors (changes in soil chemistry, microhabitat configuration), anthropogenic changes, habitat disturbance, pollution, which led to their recognition and use as bioindicators in agroecosystems assessment (Razo-González et al., 2014).

Environmental impact and sustainability of a given unit (farm, greenhouse, landscape, etc.) can be assessed only by comparison with similar units that are under different management or that use different practices. Although it is difficult to assign absolute values of sustainability to a given unit, comparisons with other units can indicate promising, compatible tools (Paoletti \& Bressan, 1996). Thus, comparing different farming techniques is essential to evaluate OGH environmental sustainability within organic systems of production. Systems approach in experimental work is considered as powerful tool to study agroecosystems and inter-relationships among environmental conditions, management, biological processes - with common reflection on chosen outcomes - indicators (Drinkwater, 2002), leading the opportunity to test broad and integrated hypotheses. Any agricultural practice, as part of the management system, can have immediate and legacy effect on soil arthropod community (Jabbour et al., 2016), that is why it is important to study their activity density (AD) and community structure over longer time span, within crop rotation.

Farming system determines plant communities (cash crop and often depending from the practices associated with weed flora), while arthropod communities are influenced by plants (Caballero-López et al., 2010) and it can be hypothesized that crop rotation is one of the decisive factors when assessing the effect of different management practices on soil arthropods. For example, decomposition occurs more rapidly when litter is placed beneath the plant species from which it had been derived than beneath different plant species, as confirmed by a study of Ayres et al. (2009) in a forest environment. This phenomenon is known as 'home field advantage'. Beside inputs, other management aspects, such as groundcover management, species cultivated, crop rotation, and irrigation system, also have an impact on soil arthropod population dynamics
(Lindberg et al., 2002; Mathews et al., 2004; Diekötter et al., 2010; Ebeling et al., 2014).

In warm climates, including Mediterranean regions, where humidity and temperature control in protected conditions are mostly limited to opening and closing the greenhouses, a continuous migration of organisms in and out of the greenhouse is expected (Van Lenteren, 2000). For this reason, it is crucial to study the spatio-temporal dynamics of their communities in order to assess the resilience of a given system and indication power of selected bioindicators (Kampichler \& Geissen, 2005).

The present paper is, to our knowledge, the first attempt to use soil arthropods as bioindicators of ecological sustainability in OGH production. Three systems were investigated in a twoyear rotation which included four cash crop species. In two systems, agroecological service crops - ASC [tailored use of cover crop species (Canali et al., 2015)] were cultivated during the summer, while in the third, soil was left bare. It was hypothesized that different systems of organic farming in the Mediterranean greenhouse production can have a significant effect on soil arthropod community characteristics and that, in turn, it is possible to detect individual patterns of abundance and richness of the different soil arthropod macrogroups.

\section{Materials and methods}

\section{Site description and experimental design}

The present study was carried out at the experimental farm of the Mediterranean Agronomic Institute in Bari - MAIB (Apulia region, Italy, $41^{\circ} .0536 \mathrm{~N} ; 16^{\circ} .8766 \mathrm{E}$ ) under an unheated plastic tunnel. The experimental tunnel was established in 2012 and was split into two fields; the experimental layout was a completely randomized block design with three blocks per field. Three organic farming systems (OFS) were randomly assigned to the three blocks of each field for a total of 18 plots $(4.0 \times 3.0 \mathrm{~m})$. The presented results refer to field I (including three replicates per system, with a total of nine plots), covering the period of a 2-year crop rotation (2014-2016), including four crop species (kohlrabi, lettuce, zucchini, and lamb's lettuce) and cultivation of ASC crops during summer period (fig. 1). Experimental OGH was a typical plastic tunnel for the Mediterranean region, with manual opening for humidity and temperature regulation. Tunnel was surrounded by ecological infrastructures (flowering strips), composed of different plant species, to increase biodiversity and ensure a richer pool for individuals exchange with cultivated plants inside the tunnel. A more detailed description of experimental design can be found in Tittarelli et al. (2016).

Three types of OFS were under comparison: (i) SUBST bare soil in the summer period (before cash crop cultivation) + organic commercial fertilizer (input substitution system); (ii) AGROMAN - ASC cultivation during summer (used as dead mulch or green manure before cultivation of autumn cash crop) + animal manure (from organic husbandry); and (iii) AGROCOM - ASC cultivation during summer (used as green manure before autumn cash crop) + compost produced on-farm. More details on systems and rotation are presented in table 1.

Experimental design implemented in our study was based on system approach, without having fixed experimental factors. Each system was characterized by system-dependent agricultural practices (e.g. soil fertility management), while 


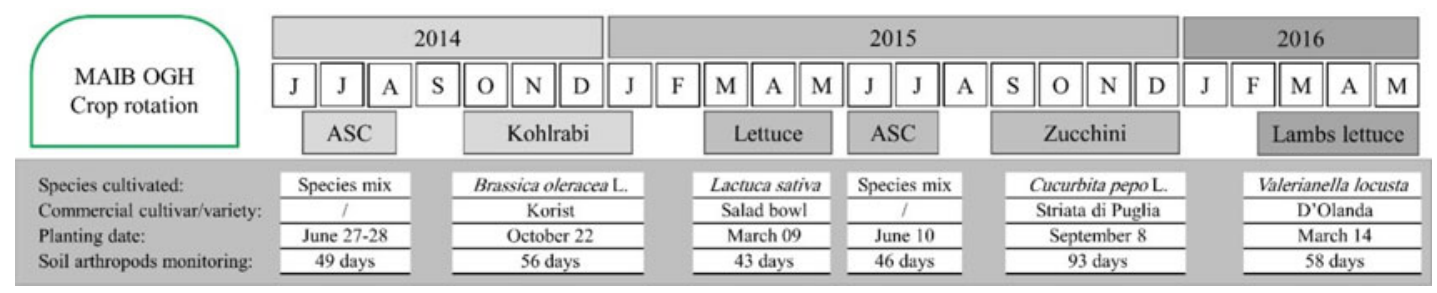

Fig. 1. Crop rotation, with planting details and duration of soil arthropod monitoring.

Table 1. System description: crop rotation, ground cover, and soil fertility management.

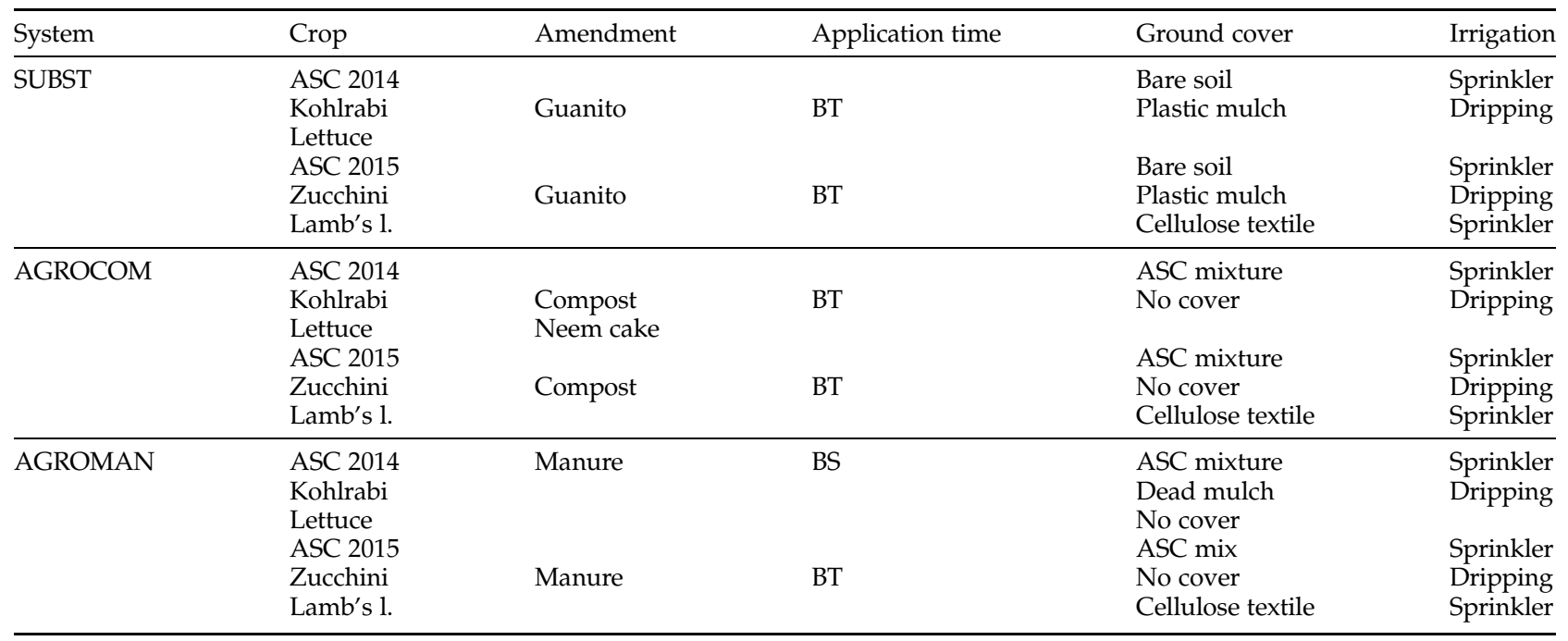

BT, before transplanting; BS, before sowing.

some of them were crop-dependent (as, e.g. ground cover management, ASC mixture composition). Soil amendment application rates were based on nitrogen $(\mathrm{N})$ supply and the need of increasing soil organic matter content. Two hundred kilograms of $\mathrm{N} /$ ha was provided to AGROMAN and AGROCOM with soil organic amendments (animal manure and compost, respectively), while $100 \mathrm{~kg}$ of $\mathrm{N} / \mathrm{ha}$, as organic fertilizer (guanito), was applied in SUBST plots. The remaining part of nutrients (to satisfy crop needs) was provided in all systems with commercial, a liquid fertilizer Kappabios (SERBIOS srl - Italy), with the following nutrient composition: total organic carbon (C) $150.0 \mathrm{~g} \mathrm{~kg}^{-1}$, total N $30.0 \mathrm{~g} \mathrm{~kg}^{-1}, \mathrm{~K}_{2} \mathrm{O}$ $60 \mathrm{~g} \mathrm{~kg}^{-1}$.

ASC cultivation was carried out in the summer period of 2014 and 2015 seasons, with the aim to provide different ecological services in AGROCOM and AGROMAN systems, i.e. soil organic matter increase, biofumigation, and dead mulch formation (Scholberg et al., 2010; Ciaccia et al., 2015). Same ASC mixture was applied in both systems in 2014, while in 2015 mixtures were different (table 2).

The plant protection program (products and application rate) was the same for all systems under assessment. It was based on the products allowed to use in organic agriculture by the European Union (EU) regulation - EC Reg. No. 834/ 2007 (EC, 2007) - copper and sulfur as active substances in case of fungal infection and pyrethrin for aphid control (in case of kohlrabi, lettuce, and zucchini).

\section{Soil arthropod monitoring}

Monitoring of soil fauna started on July 2014, following a rotation plan, until May 2016. It lasted overall for 345 days in each OGH system, depending on the crop cycle, as follows: ASC 2014 - 49 days, kohlrabi - 56 days, lettuce - 43 days, ASC 2015 - 46 days, zucchini - 93 days, and lamb's lettuce 58 days. Pitfall traps were used (one per plot - with three replicates per system) to collect arthropods. Traps position was assigned randomly, avoiding space near to plot borders. Each trap consisted of a plastic cup $(13 \mathrm{~cm} \times 10 \mathrm{~cm}, 500 \mathrm{ml})$ half filled with $50 \%$ propylene glycol water solution. The cups were dug into the soil and the rim was leveled with the soil surface. A $15 \mathrm{~cm}$ diameter plastic roof was placed $4 \mathrm{~cm}$ above the cup to prevent the overflow due to the irrigation water. The traps were replaced every 15-25 days during the monitoring period (depending on the capture rate). The content of each cup was collected in the field into a plastic container and stored in the fridge until counting in the laboratory. Arthropods captured were separated in seven macrogroups (Carabidae, Staphylinidae, Collembola, Araneae, Myriapoda, Isopoda, and Opiliones). Capture rates from pitfall traps integrate arthropod density and activity levels, providing a proxy for the magnitude of the ecological processes in which the organisms are involved (Southwood \& Henderson, 2000; Høye \& Forchhammer, 2008). Numbers trapped depend not only on the population density of a species but also on its 
Table 2. ASC mixtures cultivated in summer period 2014 and 2015 in AGROCOM and AGROMAN.

\begin{tabular}{|c|c|c|c|c|c|}
\hline Year & System (use) & ASC species mixture & Common name & Botanical family & $\%$ \\
\hline \multirow[t]{3}{*}{2014} & AGROCOM (green manure) & Pennisetum glaucum (L.) R. Br. & Pearl millet & Poacea & 30 \\
\hline & AGROMAN (dead mulch) & Setaria Italica (L.) P. Beauvois & Foxtail millet & & 30 \\
\hline & & Lablab purpureus (L.) Sweet & Lablab bean & Fabacea & 20 \\
\hline \multirow[t]{6}{*}{2015} & AGROCOM (green manure) & Raphanus sativus L. & Radish & Brassicaceae & 33 \\
\hline & & Sinapis alba $\mathrm{L}$. & White mustard & & 33 \\
\hline & & V. sinensis (L.) Savi & Cowpea & & 20 \\
\hline & & Crotalaria juncea L. & Sunn hemp & & 20 \\
\hline & & Hedysarum coronarium L. & Sulla & & 20 \\
\hline & & Onobrychis viciifolia Scop. & Sainfoin & & 20 \\
\hline
\end{tabular}

locomotory activity, as well as on habitat characteristics. Therefore, numbers caught do not allow direct estimation of population density but only of activity density (Thiele, 1977). The use of a higher taxonomic level (e.g. richness of indicator groups) in studies of soil arthropod dynamics proved to be suitable for bioindication and to reduce costs when exploring biodiversity, assessing the anthropogenic impact and guiding management decisions (Biaggini et al., 2007; Burgio et al., 2015; Gkisakis et al., 2016).

\section{Data analysis}

Total abundance of arthropods was considered as the total number of individuals captured in each management type, with the exclusion of Collembola, which are presented separately, due to their high abundance compared with others. Relative abundance of the taxa was calculated as the proportion of individuals of each group with respect to the total pooled number of individuals (including Collembola). AD was calculated by dividing the pooled number of individuals captured by the number of days of trap activity.

Soil arthropods collected were divided in two subgroups according to the functions provided by the majority of their species, as follows: (i) biological pest control (BPC) group and (ii) nutrient cycling (NC) group (Gkisakis et al., 2016). BPC subgroup included potential predators as Araneae, Carabidae, Staphylinidae, and Opiliones (Pinto da Rocha et al., 2007; Clough et al., 2007a; Woodcock et al., 2010), while NC group included decomposers and detritivores - Isopoda, Myriapoda, and Collembola (Paoletti \& Hassall, 1999; Lensing et al., 2005; Snyder \& Hendrix, 2008).

Analysis of variance (ANOVA) was performed using CoStat software (Version 6400, CoHort Software, Monterey, CA, USA). Data were square root transformed, if necessary, prior to ANOVA to satisfy assumptions of normality and homogeneity of variances. Mean separations were performed using the HSD Tukey's test $(P<0.05)$. Principal components analysis (PCA) was performed on the data for mean total abundance of soil arthropod macrogroups in the cumulative monitoring period (including all crops, for overall 345 days), using XLSTAT software (XLstat 2016; Addinsoft, New York, NY, USA).

\section{Results}

A total of 14448 arthropod individuals were collected, including 1785 for ASC 2014, 1005 for kohlrabi, 2179 for lettuce, 1514 for ASC 2015, 6466 for zucchini, and 1499 for lamb's lettuce. Mean total abundance per system, without Collembola, is presented in fig. 2. In the first year of OGH crop rotation, during ASC cultivation, the greatest abundance was recorded in AGROMAN system $(52.0 \pm 18.4)$, which showed higher values than SUBST $(14.0 \pm 4.6)$ and AGROCOM (35.0 \pm 8.2$)$. Succeeding cash crop - kohlrabi, demonstrated a different pattern, with the highest mean value recorded in AGROCOM $(46.3 \pm 15.5)$, followed by SUBST and AGROMAN with means of $32.7( \pm 21.1)$ and $22.7( \pm 4.7)$, respectively. Lettuce, the second crop in the first year of rotation, showed significantly higher values of total abundance of soil taxa in AGROCOM, with a mean of $63.3( \pm 13.9)$.

In the second year of crop rotation, AGROMAN confirmed significantly higher total abundance $(140 \pm 26.1)$ in ASC cultivation, in comparison with SUBST $(47.3 \pm 3.5)$, while AGROCOM showed an intermediate position respect to other systems, and it was characterized by high variability $(69.7 \pm 29.3)$. Total abundance of soil arthropods did not differ among systems in the period of zucchini and lamb's lettuce. Arthropod monitoring of these two crops revealed high variability for SUBST system and the highest values in AGROCOM, with a mean of $94.6( \pm 11.1)$ for zucchini and $40.7( \pm 8.5)$ in case of lamb's lettuce.

Collembola population trends are shown in fig. 3. This taxon showed significant differences among systems for ASC cultivation in both years. In 2014, SUBST system displayed the highest abundance of Collembola (353.76 \pm 21.49$)$, whereas in 2015, AGROMAN system was the most abundant $(124.67 \pm 22.82)$. For other crops, in 2-year period, significant differences for Collembola abundance were not present.

Collembola was the most represented group during whole monitoring period. This was particularly pronounced for ASC 2014 in SUBST system and during zucchini cultivation (table 3). The second abundant group for ASC 2014 in AGROCOM and AGROMAN were Isopoda, accounting for 12.8 and $21.5 \%$ of the trap catches, respectively. In AGROMAN system also, Aranea and Staphylinidae accounted for more than $10 \%$ of the total. For the period of kohlrabi and lettuce, besides Collembola, the taxon with relative abundance of more than $10 \%$ was represented by Staphylinidae (in AGROCOM). Opiliones reached $8.9 \%$ of relative abundance in lettuce for AGROMAN system, representing the highest value for this macrogroup, in the whole experiment.

Cultivation of ASC 2015 showed a different trend compared to previous year, displaying a strong decrease in Collembola, especially for AGROCOM, while Aranea, Isopoda, Myriapoda, and Staphylinidae accounted for 24.1, 
(a)

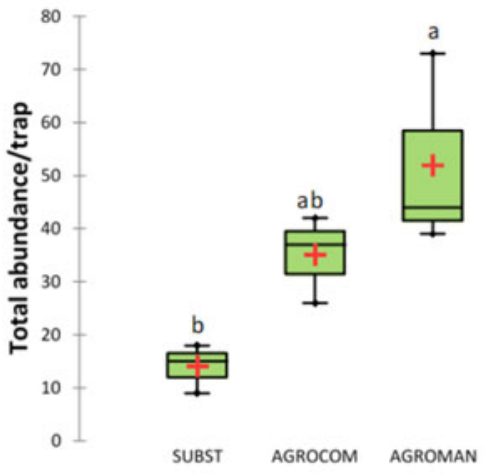

(c)

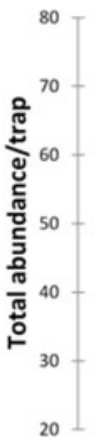

Lettuce

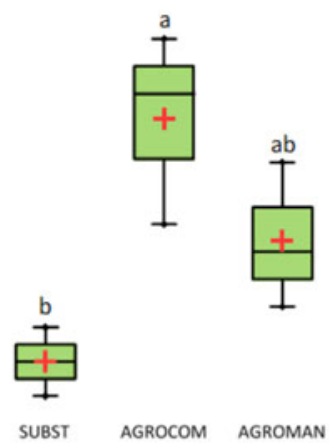

(e)

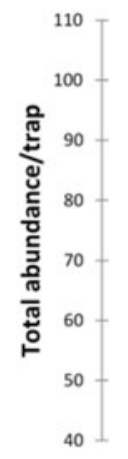

Zucchini

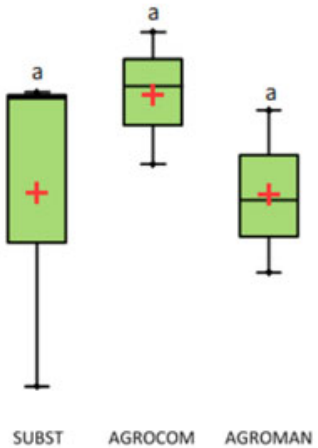

(b)

Kohlrabi

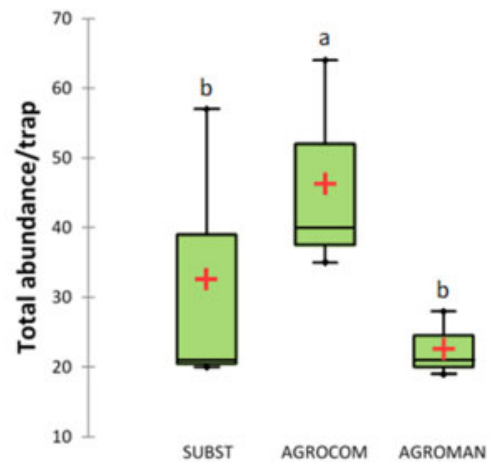

(d)

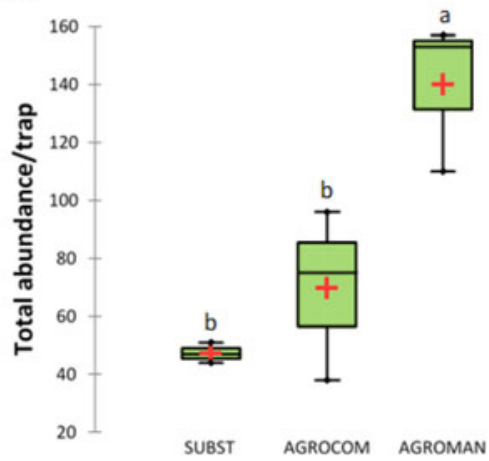

(f)

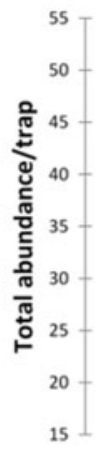

Lambs lettuce

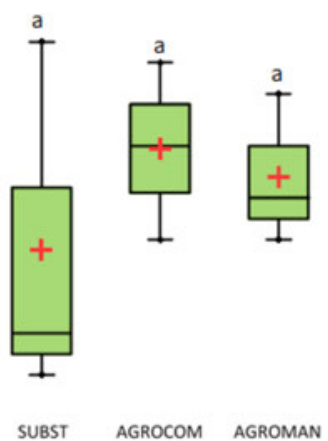

Fig. 2. Soil arthropods mean total abundance (without Collembola) per system in each crop, during a 2-year crop rotation. The thick line marks the median and cross mean of the distribution. ANOVA followed by Tukey's test $(P<0.05)$; different letters indicate significant differences.

$13.7,11.3$, and $11.3 \%$ from the total number of individuals, respectively. In SUBST, only Aranea (20.5\%), besides Collembola, showed a high relative abundance, while in AGROMAN, Aranea (20.1\%) and Isopoda (19.1\%) were the more represented taxa. Collembola dominated during zucchini and lamb's lettuce cultivation.

Table 4 presents the mean number of individuals per system and crop during the 2 years of monitoring. Data analysis for ASC 2014 cultivation showed significant differences among the systems for Aranea, Isopoda, and Staphylinidae. For these taxa, AGROMAN system displayed the highest abundance. On the contrary, Collembola was the most prevalent group in SUBST. Opiliones, Myriapoda, and Carabidae were poorly represented in all systems. Results for kohlrabi demonstrated significantly higher number of Opiliones and Staphylinidae in AGROCOM system in comparison to SUBST; also Myriapoda were higher in AGROCOM in comparison to AGROMAN. Opiliones, as previously shown, displayed the lowest number of individuals in all systems. In the following crop (lettuce), which was cultivated during spring period, Opiliones increased their number in all systems and were significantly more abundant in 


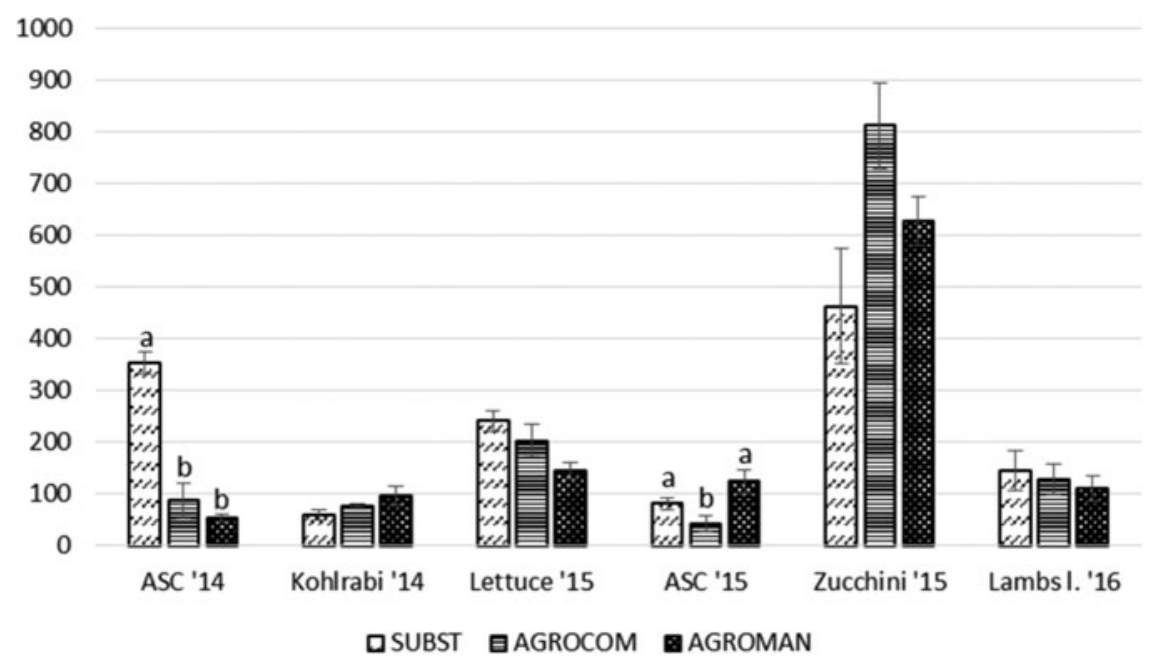

Fig. 3. Total abundance of Collembola (mean \pm standard error) per system in each crop, during a 2-year crop rotation. ANOVA followed by Tukey's test $(P<0.05)$; different letters within one crop indicate significant differences.

Table 3. Relative abundance (\%) of soil arthropods in experimental OGH systems during a 2-year crop rotation.

\begin{tabular}{|c|c|c|c|c|c|c|c|c|c|c|}
\hline \multirow{2}{*}{$\begin{array}{l}\text { Crop } \\
\text { System }\end{array}$} & & \multicolumn{3}{|c|}{ ASC 2014} & \multicolumn{3}{|c|}{ Kohlrabi 2014} & \multicolumn{3}{|c|}{ Lettuce 2015} \\
\hline & & SUBST & $\mathrm{AC}$ & $\mathrm{AM}$ & SUBST & $\mathrm{AC}$ & $\mathrm{AM}$ & SUBST & $\mathrm{AC}$ & $\mathrm{AM}$ \\
\hline \multirow[t]{4}{*}{ Macrogroup (\%) } & Carabidae & 0.2 & 2.7 & 0.6 & 5.1 & 5.9 & 0.8 & 0.2 & 0.6 & 0.7 \\
\hline & Opiliones & 0.0 & 0.5 & 0.0 & 0.7 & 3.2 & 0.8 & 1.7 & 4.6 & 8.9 \\
\hline & Isopoda & 1.3 & 12.8 & 21.5 & 15.2 & 5.1 & 3.4 & 2.1 & 2.9 & 3.9 \\
\hline & Myriapoda & 0.2 & 1.6 & 1.6 & 2.9 & 3.5 & 0.6 & 0.2 & 0.7 & 0.7 \\
\hline \multirow{2}{*}{$\begin{array}{l}\text { Crop } \\
\text { System }\end{array}$} & & \multicolumn{3}{|c|}{ ASC 2015} & \multicolumn{3}{|c|}{ Zucchini 2015} & \multicolumn{3}{|c|}{ Lamb's lettuce 2016} \\
\hline & & SUBST & $\mathrm{AC}$ & $\mathrm{AM}$ & SUBST & $\mathrm{AC}$ & $\mathrm{AM}$ & SUBST & $\mathrm{AC}$ & $\mathrm{AM}$ \\
\hline \multirow[t]{3}{*}{ Macrogroup (\%) } & Carabidae & 0.5 & 0.9 & 0.6 & 0.7 & 0.9 & 0.8 & 0.4 & 0.2 & 0.9 \\
\hline & Aranea & 20.5 & 24.1 & 20.1 & 5.2 & 3.2 & 2.5 & 2.4 & 3.2 & 2.9 \\
\hline & Opiliones & 0.5 & 0.9 & 0.1 & 0.3 & 1.1 & 1.7 & 2.5 & 4.4 & 4.5 \\
\hline
\end{tabular}

AGROMAN in comparison with SUBST, while Staphylinidae were more abundant in AGROCOM, against the other systems. Carabidae and Myriapoda were poorly represented in all systems.

In ASC 2015 cultivation, Isopoda, Myriapoda, and Staphylinidae showed a higher population in AGROMAN in comparison with SUBST. Similarly, Aranea and Collembola showed highest presence in AGROMAN, being significantly higher than in other two systems. In this case, Carabidae and Opiliones were represented by a very low number of individuals. In zucchini cultivation only Opiliones displayed significant differences among systems; this taxon was significantly more abundant in AGROMAN $(12.0 \pm 0.6)$ and AGROCOM $(9.7 \pm 2.9)$, in comparison to SUBST $(1.7 \pm 0.9)$. No significant differences of soil taxa were detected among the systems, during lamb's lettuce cultivation.
Soil arthropod's AD did not show a constant pattern among systems over the 2 years (fig. 4). SUBST with AD value of $7.5( \pm 0.4)$ for ASC 2014 significantly differed from AGROCOM $(2.9 \pm 0.8)$ and AGROMAN (2.1 \pm 0.2$)$. There were no statistically significant differences among systems for kohlrabi crop. In all systems, AD increased during lettuce cultivation, being $6.3( \pm 0.4)$ in SUBST, $6.2( \pm 0.7)$ in AGROCOM, and $4.4( \pm 0.3)$ in AGROMAN, without being significantly different.

ASC 2015 cultivation, as in 2014, revealed statistically significant differences of AD among systems. AGROMAN (5.7 \pm $0.4)$ had significantly higher value compared with SUBST $(2.8 \pm 0.2)$, with intermediate AGROCOM $(3.5 \pm 0.8)$.

During zucchini cultivation, soil arthropod's AD retained significant differences among systems. AGROCOM had the highest value $(9.6 \pm 0.9)$, significantly differing from SUBST 


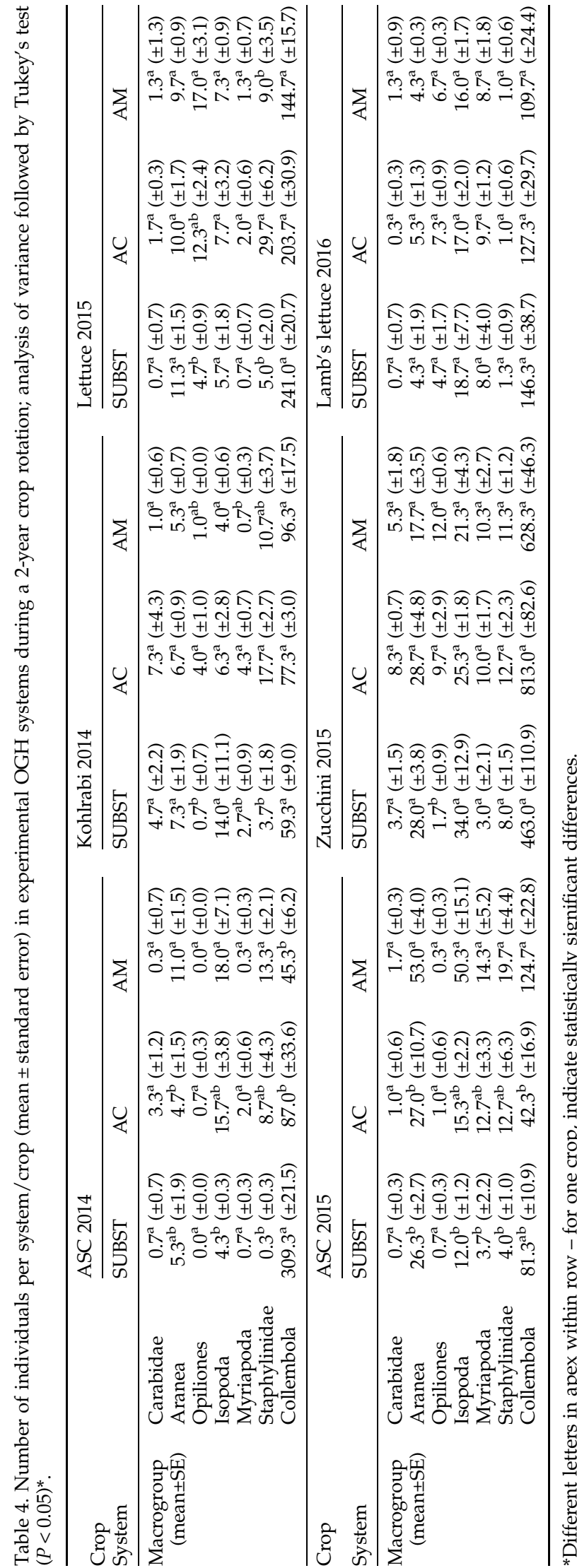

$(5.8 \pm 1.4)$ while an intermediate value for AGROMAN $(7.5 \pm$ 0.4) was observed. During lamb lettuce cultivation, AD did not differ among systems.

Considering the functional criterion for soil fauna (table 5), AGROCOM and AGROMAN showed significantly higher values for BPC subgroup, while number of individuals for NC subgroup was similar in the three systems.

PCA ordination biplot (fig. 5) explained $65.14 \%$ of the variance, being the contribution of the first and second axes $40.99 \%$ and $24.15 \%$, respectively. The multivariate ordination of soil taxa and systems evinced that AGROCOM and AGROMAN displayed a strong correlation with all soil taxa with the exception of Collembola, which clustered toward SUBST system. Staphylinidae, Carabidae, Isopoda, Opiliones, and Myriapoda were grouped close to the AGROCOM and AGROMAN, while the role of Aranea was less clear.

\section{Discussion}

Our results demonstrated a strong dependency of soil arthropod populations on the crop and farming system under investigation, displaying significant differences in the case of ASC, kohlrabi, and lettuce. On the contrary, lamb's lettuce and zucchini did not reveal significant differences in total arthropod abundance among the different systems. In the case of lamb's lettuce, this could be associated with homogeneity of ground cover management (cellulose textile with incorporated seeds in all systems, for weed control as an additional purpose). This is in line with the conclusion of Sanguankeo \& León (2011), who demonstrated that weed management practices that promote higher plant diversity and density had potential to increase the abundance of beneficial soil arthropods. For zucchini, where Collembola contributed with more than $85 \%$ of relative abundance, the other macrogroups did not demonstrate significant differences among the systems. The effect of the plastic mulch (that was applied in SUBST system during zucchini cultivation) was not pronounced, although we expected the opposite. In general, this type of mulching is not well studied in relation to soil arthropods. Kikas \& Luik (2002) found that plastic mulch increased the number of beneficial Carabidae species, whereas in the study of Tuovinen et al. (2006), the effect of plastic mulch on Carabidae was species-dependent, with positive effects for smaller specimens. Both studies were carried out on strawberries, comparing plastic mulch to other plant-originating dead mulches.

Total abundance of Collembola was significantly different among systems only during ASC cultivation. Previous studies demonstrated that high root biomass of grasses increases Collembola abundance (Milcu et al., 2006; Endlweber \& Scheu, 2007), while our results, especially for 2014, take to different conclusions, having bare soil (SUBST system) the highest Collembola captures. Collembola populations are known to be sensitive to soil disturbance (Kracht \& Schrader, 1997; Wardle et al., 1999) and changes in soil moisture (Lensing et al., 2005). Tillage was the same in all systems, but AGROMAN and AGROCOM were subjected to sowing and sprinkler irrigation, which represented a possible factor of disturbance to Collembola. The biomass production of ASC mixtures could cause depletion of nutrients in soil, thus reducing fungal growth and finally amount of food resources available for Collembola (Eisenhauer et al., 2011), which are known to be fungal grazers (Hopkin, 1997). This interpretation could 


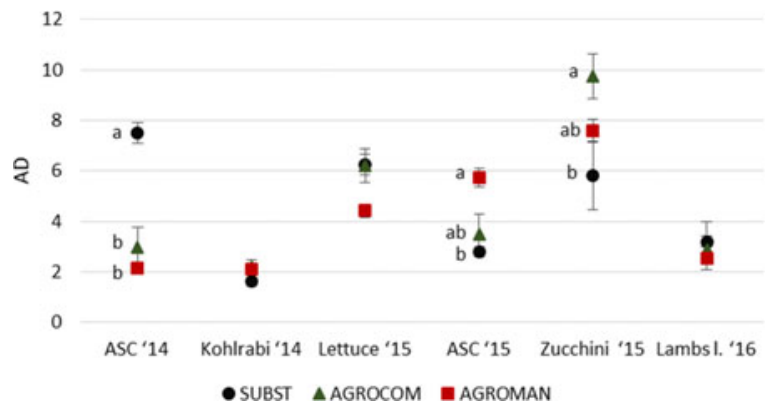

Fig. 4. Activity density (AD) of the total number of soil arthropods (pooled number of individuals in system/number of pitfall trap active days) in experimental systems during a 2-year crop rotation (mean \pm standard error). ANOVA followed by Tukey's test $(P<0.05)$; different letters within one crop indicate significant differences.

Table 5. Total abundance of functional subgroups per system (mean \pm standard error).

\begin{tabular}{lcrr}
\hline $\begin{array}{l}\text { Group/ } \\
\text { system }\end{array}$ & SUBST & AGROCOM & AGROMAN \\
\hline BPC & $130.7( \pm 7.9)^{\mathrm{b}}$ & $222.0( \pm 11.6)^{\mathrm{a}}$ & $217.0( \pm 7.1)^{\mathrm{a}}$ \\
NC & $1452.3( \pm 129.4)^{\mathrm{a}}$ & $1479.0( \pm 165.0)^{\mathrm{a}}$ & $1315.7( \pm 81.2)^{\mathrm{a}}$ \\
\hline
\end{tabular}

ANOVA followed by Tukey's test $(P<0.05)$; different letters within the row indicate significant differences.

$\mathrm{BPC}$, biological pest control; NC, nutrient cycling.

explain the particular behavior of Collembola population in our experiment.

Collembola macrogroup dominated all systems and crops over the 2-year crop rotation. This trend was more pronounced in SUBST system, while AGROCOM and AGROMAN presented more evenness of other groups, especially during ASC cultivation. In the work of Wang et al. (2016), the application of organic fertilizers increased the abundance of soil arthropods, but it did not have an effect on the total taxonomical richness in poplar plantation. On the contrary, application of organic fertilizers in maize promoted diversity of soil arthropod communities (Zhu \& Zhu, 2015), and in longterm experiment on wheat, organic fertilizers had positive effects on spider abundance (Birkhofer et al., 2008). Here, comparison is done in protected conditions and with considerably different agricultural crops and methods of cultivation, due to the lack of studies on horticultural crops.

Staphylinidae taxon was mainly associated with AGROCOM and AGROMAN, except for corn salad. Species of this group are characterized by a rapid response to changes of habitat conditions, and for this reason, they are recognized as bioindicators (Bohac, 1999). Crop type can affect their dynamics (Nasir et al., 2015) and they are known as generalist predators (Good \& Giller, 1991; Collins et al., 2002). Majority of Staphylinidae species can fly and they actively move between natural habitats and agricultural land (Clough et al., 2007b). The presence of ecological infrastructure (flowering strips) around the experimental OGH could have promoted arthropod movement to greenhouse crops, which could have provided alternative preys (e.g. aphids) and shelter (dead mulch in AGROMAN during kohlrabi, ASC crops cultivated).

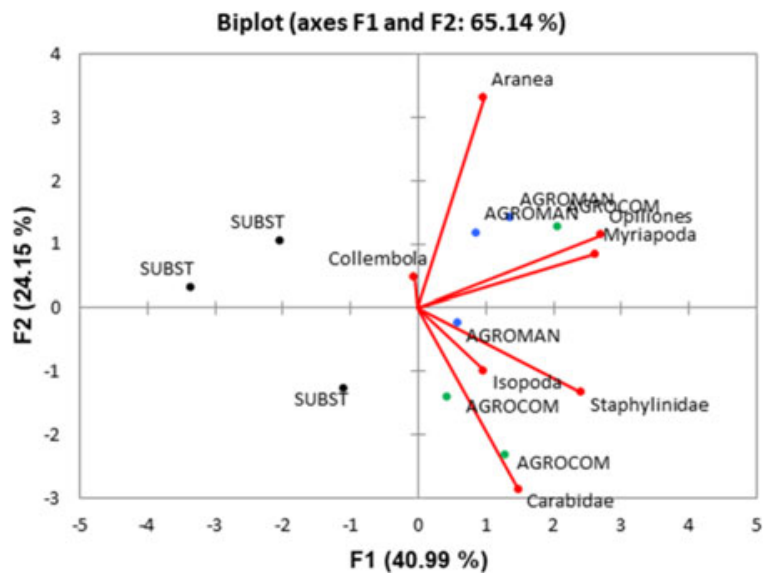

Fig. 5. Principal component analysis (PCA) ordination biplot for the soil arthropod macrogroups as response variables (arrows) and OGH systems (symbols) as explanatory variables for the cumulative monitoring period (345 days).

The higher presence of Staphylinidae in systems with compost and manure application could be explained also by an enrichment of the food chain in these systems (i.e. incorporation of organic amendments to soil could attract other arthropods that are not harmful for plants), which were able to maintain a high number of Staphylinidae individuals (Bell et al., 2008).

Beside Collembola and Staphylinidae, the macrogroups with more notable presence in two seasons were Isopoda and Aranea. In both years of ASC cultivation, AGROMAN had significantly higher number of Isopods compared with SUBST. AGROMAN favored Aranea presence as well in both years of ASC cultivation, being significantly higher than in other systems. Isopod abundance is affected by humidity and food availability (Paoletti \& Hassall, 1999) and incorporation of biomass produced from ASC cultivation represents a rich source of litter as food for Isopods, while manure application could increase water retention capacity of soil in AGROMAN system. Since ASC are cultivated as well in the AGROCOM system, differences in mean number of Isopods for those two systems could be explained by differences in $\mathrm{C} / \mathrm{N}$ ratio of ASC mixtures cultivated and soil amendments applied. In previous studies, Aranea demonstrated positive reaction and increased abundance in case of agricultural diversification (e.g. intercropping or cover crop cultivation) (Sunderland \& Samu, 2000). This is partially confirmed by our results (for AGROMAN system), but in case of Isopods, the higher number of individuals was not persistent in the following cash crops for both years of rotation. For Aranea, results obtained indicate different findings in comparison with those of Cárdenas et al. (2012), where cover crop removal did not have any effect on Aranea community dynamics.

The other groups (Carabidae, Opiliones, and Myriapoda) were represented by very low populations, and did not respond to the different OGH production systems, with the exception of Opiliones (on lettuce) and Myriapoda (on ASC 2015): in these cases both macrogroups were more abundant in AGROMAN system. Their activity was higher in spring crops (lettuce and lamb's lettuce), and this behavior could be linked to seasonal changes, rather than crop effects, since the biological peak of their activity is in spring time (Pinto da Rocha et al., 2007). Myriapoda play a role in the first step of 
leaf litter fragmentation (Snyder \& Hendrix, 2008). Unfortunately, due to the very low $A D$, their potential as bioindicators of ecological sustainability in the Mediterranean greenhouse production is questionable. Same consideration can be done for Carabidae, which were very poorly represented in our study.

Effects of each system varied among crops, without clear patterns. Most of the differences among crops could be attributed to seasonal fluctuations, while system effects were evidenced in both years of ASC and for zucchini. Effects of organic farming on AD of some soil arthropods were contrasting in previous studies, where organic production is compared to conventional, accounting no or negative effect (Diekötter et al., 2010; Ekroos et al., 2010) or positive effect (Burgio et al., 2015). In all the cases, the responses were dependent by the crop and taxon considered. Field studies within organic farming demonstrated that some agricultural practices as living mulch promoted different effects on beneficial arthropods, being taxon-dependent (Depalo et al., 2016).

Functional group analysis revealed strong potential of AGROMAN and AGROCOM for pest suppression, leading to a potential for increasing resilience in a long-term evaluation. Functional grouping carried out in this work cannot be strictly compared to other cases, for the reason of having different macrogroups included as bioindicators.

Despite the low number of individuals for some groups (Carabidae, Opiliones, and Myriapoda), PCA displayed their association with AGROMAN and AGROCOM. In general, PCA is useful for studies with several arthropod macrogroups since it can provide more deep perception of ecological interactions, by identifying macrogroups with opposite responses to a given treatment (system) (Frampton et al., 2000). In our study, PCA was able to clearly discriminate SUBST from AGROMAN and AGROCOM, confirming the difference of these systems on the basis of arthropod diversity. The fact is that pitfall catches are a function of the species' true population size and its AD creates specific statistical problems (Kotze et al., 2011). This is partially solved with square root transformation, but longer and continuous sampling is the best solution to increase data confidentiality, as in the case of our study. Another problem occurs when the AD results for different species are compared. Since each species reacts differently to pitfall traps, their 'catchability' will also differ, subsequently with more or less incomparable results between species. Here employment of PCA analysis proved to be a good solution to analyze the data, with clear separation of SUBST system.

As already reported in a recently published paper with the same experimental approach (Tittarelli et al., 2016), the results obtained showed that organic production systems are not all the same. A 'conventionalized' organic production system (based on an input substitution approach) in protected conditions guarantees a different level of environmental sustainability and of resilience respect to organic production systems, where soil fertility management is based not only on organic fertilizers application, but also on organic amendments and green manure incorporation to soil.

\section{Conclusion}

The results of our study corroborate the role of soil arthropods as bioindicators in OGH production, in a twoseason study, involving four different cash crops and ASC cultivation, including different fertilization strategies and agricultural practices.

Further, our results demonstrate suitability of the selected macrogroups in assessing the ecological sustainability of Mediterranean OGH production. Moreover, the following concluding notes can be made: (i) suitability of Carabidae, in our environmental condition, to be part of indicator set should be revised, since low number of individuals does not allow adequate data processing ; (ii) groups totaling small number of individuals (Myriapoda and Opiliones) should be further explored on the basis of a functional trait approach; (iii) groups like Staphylinidae seem to be responsive as a bioindicator to characterize OFS in greenhouse conditions (in terms of different agricultural practices and crops), and their ecological role should be investigated in future research.

In conclusion, as shown by our experimental design applying agroecological approach, or diversification of agricultural practices, in OGH, production could lead to higher ecological sustainability, biodiversity conservation, and improvement of system resilience. Ecological quality assessment of greenhouse production is a complex procedure and the use of soil indicators could provide a standard way to measure ecological sustainability. Further studies should investigate the role of soil bioindicators in food webs in greenhouses in order to explain the influence of these functional groups on biological control against pests, nutrient cycles, and other ecosystem services.

\section{Acknowledgements}

The present research has been carried out in the framework of the project BIOSEMED (MIPAAF DM 24/12/2013 n.63764). The research concerning organic greenhouse production is included in the activities of the COST action FA1105 - 'Towards a sustainable and productive EU organic greenhouse horticulture' and it is a part of MORE GREEN Long Term Experiment (RETIBIO Project funded by Mipaaf 25865 01/12/2014). Special thanks to insectarium staff and field workers of MAI-Bari.

\section{References}

Andre, H.M., Duarme, X. \& Lebrum, P. (2002) Soil biodiversity: myth, reality or conning? Oikos 96, 3-24.

Ayres, E., Steltzer, H., Simmons, B.L., Simpson, R.T., Steinweg, J. M., Wallenstein, M.D., Mellor, N., Parton, W.J., Moore, J.C. \& Wall, D.H. (2009) Home-field advantage accelerates leaf litter decomposition in forests. Soil Biology and Biochemistry 41, 606-610.

Bell, J.R., Traugott, M., Sunderland, K.D., Skirvin, D.J., Mead, A., Kravar-Garde, L., Reynolds, K., Fenlon, J.S. \& Symondson, W.O.C. (2008) Beneficial links for the control of aphids: the effects of compost applications on predators and prey. Journal of Applied Ecology 45, 1266-1273.

Bengtsson, J., Ahnström, J., Weibull, A. \& Weibull, A.C. (2005) The effects of organic agriculture on biodiversity and abundance: a meta-analysis. Journal of Applied Ecology 42, 261-269.

Biaggini, M., Consorti, R., Dapporto, L., Dellacasa, M., Paggetti, E. \& Corti, C. (2007) The taxonomic level order as a possible tool for rapid assessment of arthropod diversity in agricultural landscapes. Agriculture, Ecosystem E Environment 122, 183-191.

Birkhofer, K., Bezemer, T.M., Bloem, J., Bonkowski, M., Christensen, S., Dubois, D., Ekelund, F., Fliessbach, A., Gunst, L., Hedlund, K., Mader, P., Mikola, J., Robin, C., 
Setala, H., Tatin-Froux, F., Van der Putten, W.H. \& Scheu, S. (2008) Long term organic farming fosters below and aboveground biota: implications for soil quality, biological control and productivity. Soil Biology and Biochemistry 40, 2297-2308.

Bohac, J. (1999) Staphylinid beetles as bioindicators. Agriculture, Ecosystem E Environment 74, 357-372.

Burgio, G., Campanelli, G., Leteo, F., Ramilli, F., Depalo, L., Fabbri, R. \& Sgolastra, F. (2015) Ecological sustainability of an organic four-year vegetable rotation system: carabids and other soil arthropods as bioindicators. Agroecology and Sustainable Food Systems 39, 295-316.

Caballero-López, B., Blanco-Moreno, J.M., Pérez, N., Pujade-Villar, J., Ventura, D., Oliva, F. \& Sans, F.X. (2010) A functional approach to assessing plant-arthropod interaction in winter wheat. Agriculture, Ecosystem \& Environment 137, 288-293.

Canali, S., Diacono, M., Campanelli, G. \& Montemurro, F. (2015) Organic no-till with roller crimpers: agro-ecosystem services and applications in organic Mediterranean vegetable productions. Sustainable Agriculture Research 4, 66-75.

Cárdenas, M., Castro, J. \& Campos, M. (2012) Short-term response of soil spiders to cover-crop removal in an organic olive orchard in a Mediterranean setting. Journal of Insect Science 12, 1-18.

Ciaccia, C., Testani, E., Campanelli, G., Sestili, S., Leteo, F., Tittarelli, F., Riva, F., Canali, S. \& Trinchera, A. (2015) Ecological service providing crops effect on melon-weed competition and allelopathic interactions. Organic Agriculture 5, 199-207.

Clough, Y., Holzschuh, A., Gabriel, D., Purtauf, T., Kleijn, D., Kruess, A., Steffan-Dewenter, I. \& Tscharntke, T. (2007a) Alpha and beta diversity of arthropods and plants in organically and conventionally managed wheat fields. Journal of Applied Ecology 44, 804-812.

Clough, Y., Kruess, A. \& Tscharntke, T. (2007b) Organic versus conventional arable farming systems: functional grouping helps understand Staphylinid response. Agriculture, Ecosystem \& Environment 118, 285-290.

Collins, K.L., Boatman, N.D., Wilcox, A., Holland, J.M. \& Chaney, K. (2002) Influence of beetle banks on cereal aphid predation in winter wheat. Agriculture, Ecosystem \& Environment 93, 337-350.

Depalo, L., Burgio, G., Von Fragstein, P., Kristensen, H.L., Bavec, M., Robačer, M., Campanelli, G. \& Canali, S. (2016) Impact of living mulch on arthropod fauna: analysis of pest and beneficial dynamics on organic cauliflower (Brassica oleracea L. var. botrytis) in different European scenarios. Renewable Agriculture and Food Systems 32, 1-8.

Diekötter, T., Wamser, S., Wolters, V. \& Birkhofer, K. (2010) Landscape and management effects on structure and function of soil arthropod communities in winter wheat. Agriculture, Ecosystem \& Environment 137, 108-112.

Drinkwater, L.E. (2002) Cropping systems research: reconsidering agricultural experimental approaches. HortTechnology 12, 355-361.

Ebeling, A., Pompe, S., Baade, J., Eisenhauer, N., Hillebrand, H., Proulx, R., Roscher, C., Schmid, B., Wirth, C. \& Weisser, W.W. (2014) Plant diversity impacts decomposition and herbivory via changes in aboveground arthropods. PLOS ONE 9, e106529.

EC [European Council] (2007) Council regulation (EC) No 834/ 2007 on organic production and labeling of organic products and repealing Regulation (EEC) No 2092/91. O.J. of the European Union of the 20/07/2007 L 189/1.
Eisenhauer, N., Sabais, A.C.W. \& Scheu, S. (2011) Collembola species composition and diversity effects on ecosystem functioning vary with plant functional group identity. Soil Biology and Biochemistry 43, 1697-1704.

Ekroos, J., Hyvonen, T., Tiainen, J. \& Tiira, M. (2010) Responses in plant and carabid communities to farming practises in boreal landscapes. Agriculture, Ecosystem E Environment 135, 288-293.

Endlweber, K. \& Scheu, S. (2007) Interactions between myccorhizal fungi and Collembola: effects on root structure of competing plant species. Biology and Fertility of Soils 43, 741-749.

Frampton, G.K., Van Den Brink, P.J. \& Gould, P.J.L. (2000) Effects of spring drought and irrigation on farmland arthropods in southern Britain. Journal of Applied Ecology 37, 865-883.

Gkisakis, V., Volakakis, N., Kollaros, D., Barberi, P. \& Kabourakis, E.M. (2016) Soil arthropod community in the olive agroecosystem: determined by environment and farming practices in different management systems and agroecological zones. Agriculture, Ecosystem \& Environment 218, 178-189.

Good, J.A. \& Giller, P.S. (1991) The effect of cereal and grass management on Staphylinid (Coleoptera) assemblages in South West Ireland. Journal of Applied Ecology 28, 810-826.

Goldberger, J.R. (2011) Conventionalization, civic engagement, and the sustainability of organic agriculture. Journal of Rural Studies 27, 288-296.

Hall, A. \& Mogyorody, V. (2001) Organic farmers in Ontario: an examination of the conventionalization argument. Sociologia Ruralis 41, 399-422.

Hole, D.G., Perkins, A.J., Wilson, J.D., Alexander, I.H., Grice, P. V. \& Evans, A.D. (2005) Does organic farming benefit biodiversity? Biological Conservation 122, 113-130.

Hopkin, S.P. (1997) Biology of the Springtails (Insecta: Collembola). New York, Oxford University Press.

Høye, T. T. \& Forchhammer, M. C. (2008) The influence of weather conditions on the activity of high arctic arthropods inferred from long-term observations. BMC Ecology 8, 8.

Jabbour, R., Pisani-Gareau, T., Smith, R.G., Mullen, C. \& Barbercheck, M. (2016) Cover crop and tillage intensities alter ground-dwelling arthropod communities during the transition to organic production. Renewable Agriculture and Food Systems 31, 361-374.

Kampichler, C. \& Geissen, V. (2005) Temporal predictability of soil microarthropod communities in temperate forests. Pedobiologia 49, 41-50.

Kikas, A. \& Luik, A. (2002) The influence of different mulches on strawberry yield and beneficial entomofauna. Acta Horticulturae $567,701-704$.

Kotze, D.J., Brandmayr, P., Casale, A., Dauffy-Richard, E., Dekoninck, W., Koivula, M.J., Lövei, G.L., Mossakowski, D., Noordijk, J., Paarmann, W., Pizzolotto, R., Saska, P., Schwerk, A., Serrano, J., Szyszko, J., Taboada, A., Turin, H., Venn, S., Vermeulen, R. \& Zetto, T. (2005) Forty years of carabid beetle research in Europe - from taxonomy, biology, ecology and population studies to bioindication, habitat assessment and conservation. ZooKeys 100, 55-148.

Kracht, M. \& Schrader, S. (1997) Collembola and Acari in compacted soil of agricultural land under different soil tillage systems. Braunschweiger Naturkundliche Schriften 5, 425-440.

Kromp, B. (1999) Carabid beetles in sustainable agriculture: a review on pest control efficacy, cultivation impacts and enhancement. Journal of Applied Ecology 74, 187-228.

Lensing, J.R., Todd, S. \& Wise, D.H. (2005) The impact of altered precipitation on spatial stratification and activity-densities of 
springtails (Collembola) and spiders (Araneae). Ecological Entomology 30, 194-200.

Lindberg, N., Engtsson, J.B. \& Persson, T. (2002) Effects of experimental irrigation and drought on the composition and diversity of soil fauna in a coniferous stand. Journal of Applied Ecology 39, 924-936.

Mathews, C.R., Bottrell, D.G. \& Brown, M.W. (2004) Habitat manipulation of the apple orchard floor to increase ground-dwelling predators and predation of Cydia pomonella (L.) (Lepidoptera: Tortricidae). Biological Control 30, 265-273.

Milcu, A., Partsch, S., Langel, R. \& Scheu, S. (2006) The response of decomposers (earthworms, springtails and microorganisms) to variations in species and functional group diversity of plants. Oikos 112, 513-524.

Nasir, S., Akram, W., Zahid, F.M., Ahmed, F., Hussain, S.M. \& Nasir, I. (2015) Effect of crop type and production systems (conventional and organic agriculture) on the density of rove beetles (Staphylinidae: Coleoptera) in the Punjab, Pakistan. Journal of the Kansas Entomological Society 88, 1-9.

Paoletti, M.G. \& Bressan, M. (1996) Soil invertebrates as bioindicators of human disturbance. Critical Reviews in Plant Sciences 15, 21-62.

Paoletti, M.G. \& Hassall, M. (1999) Woodlice (Isopoda: Oniscidea): their potential for assessing sustainability and use as bioindicators. Journal of Applied Ecology 74, 157-165.

Pinto da Rocha, R., Machado, G. \& Giribet, G. (2007) Harvestman - The Biology of Opiliones. USA, Harvard University Press.

Randall, N.P. \& James, K.L. (2012) The effectiveness of integrated farm management, organic farming and agri-environment schemes for conserving biodiversity in temperate Europe - a systematic map. Environmental Evidence 1, 1-21.

Razo-González, M., Castaño-Meneses, G., Callejas-Chavero, A., Pérez-Velázquez， D. \& Palacios-Vargasa, J.G. (2014) Temporal variations of soil arthropods community structure in El Pedregal de San Ángel Ecological Reserve, Mexico City, Mexico. Applied Soil Ecology 83, 88-94.

Sanguankeo, P.P. \& León, R.G. (2011) Weed management practices determine plant and arthropod diversity and seed predation in vineyards. Weed Research 51, 404-412.

Southwood, T.R.E. \& Henderson, P.A. (2000). Ecological Methods. Oxford, Blackwell Science.

Scholberg, J.M.S., Dogliott, S., Zotarelli, L., Cherr, C.M., Leoni, C. \& Rossing, W.A.H. (2010) Cover crops in agrosystems, innovations and applications. pp. 59-98 in Lichtfouse, E. (ed.), Sustainable Agriculture Reviews 4: Genetic Engineering,
Biofertilisation, Soil Quality and Organic Farming. Dordrecht, The Netherlands, Springer.

Smeding, F.W. \& de Snoo, G.R. (2003) A concept of food-web structure in organic arable farming systems. Landscape and Urban Planning 65, 219-236.

Snyder, B.A. \& Hendrix, P.F. (2008) Current and potential roles of soil macroinvertebrates (earthworms, millipedes, and isopods) in ecological restoration. Restoration Ecology 16, 629-636.

Sunderland, K. \& Samu, F. (2000) Effects of agricultural diversification on the abundance, distribution, and pest control potential of spiders: a review. Entomologia Experimentalis et Applicata 95, 1-13.

Thiele, H. U. (1977). Carabid Beetles in Their Environment. New York, Springer.

Tittarelli, F., Ceglie, F.G., Ciaccia, C., Mimiola, G., Amodio, M.L. \& Colelli, G. (2016) Organic strawberry in Mediterranean greenhouse: effect of different production systems on soil fertility and fruit quality. Renewable Agriculture and Food Systems First View, 1-13.

Tuovinen, T., Kikas, A., Tolonen, T. \& Kivijärvi, P. (2006) Organic mulches vs. black plastic in organic strawberry: does it makes a difference for ground beetles (Col., Carabidae)? Journal of Applied Entomology 130, 495-503.

Van Lenteren, J.C. (2000) A greenhouse without pesticides: fact or fantasy? Crop Protection 19, 375-384.

Van Straalen, N.M. (1998) Evaluation of bioindicator systems derived from soil arthropod communities. Applied Soil Ecology 9, 429-437.

Wang, S., Chen, H.Y., Tan, Y., Fan, H. \& Ruan, H. (2016) Fertilizer regime impacts on abundance and diversity of soil fauna across a poplar plantation chronosequence in coastal Eastern China. Scientific Reports 6, 208-216.

Wardle, D.A., Nicholson, K.S., Bonner, K.I. \& Yeates, G.W. (1999) Effects of agricultural intensification on soil-associated arthropod population dynamics, community structure, diversity and temporal variability over a seven-year period. Soil Biology and Biochemistry 31, 1691-1706.

Woodcock, B.A., Redheada, J., Vanbergenb, A.J., Hulmesa, L., Hulmesa, S., Peytona, J., Nowakowskic, M., Pywella, R.F. \& Hearda, M.S. (2010) Impact of habitat type and landscape structure on biomass, species richness and functional diversity of ground beetles. Journal of Applied Ecology 139, 181-186.

Zhu, X. \& Zhu, B. (2015) Diversity and abundance of soil fauna as influenced by long term fertilization in cropland of purple soil, China. Soil and Tillage Research 146, 39-46. 